\title{
Living with Earthquakes: Educating masses through earthquake awareness: North East (NE) India perspective
}

\author{
Chandan Dey ${ }^{1,2}$, Santanu Baruah ${ }^{*}, 1,2$, Bijit Kr Choudhury ${ }^{1}$, Timangshu Chetia ${ }^{1}$, \\ Sowrav Saikia ${ }^{3}$, Antara Sharma ${ }^{1}$, and Manoj K Phukan ${ }^{1}$ \\ (1) CSIR-North East Institute of Science \& Technology, Jorhat, Assam-785006 \\ (2) Academy of Scientific and Innovative Research, Ghaziabad, UP - 201002 \\ (3) National Center for Seismology, Ministry of Earth Sciences, New Delhi-110003
}

Article history: received April 28, 2020; accepted December 18, 2020

\begin{abstract}
Earthquake is one of the most frightening and destructive phenomena of nature. In this context, attention may be drawn on the intense seismicity, accentuated by the tectonic configuration, of the NE India region and its adjoining south and southeast Asian neighbours including Bhutan, Nepal, Myanmar and Bangladesh. The region, categorized under the highest level of seismic hazard potential: Zone $V$ of the seismic zonation map of India, is visited by 22 large $(M \geqslant 7.0)$ and two great earthquakes (M S 8.7) in the past 130 years. All these earthquakes caused extensive damage and inflicted unbridled misery and hysteria. In the recent past, the NE India region has witnessed rapid urbanization with a significant rise in population relative to the period when these great/large earthquakes occurred and therefore the seismic vulnerability index has increased manifold. The situation demands for widespread dissemination of seismic hazard preparedness through community participation and highlighting on the potential consequences of earthquakes by carrying out extensive mock drill exercises and earthquake awareness programmes. In this paper, the role of statuary bodies viz. National Disaster Management Authority (NDMA), CSIR - North East Institute of Science and Technology (CSIR-NEIST) and PhD societal programme (CSIR 800) of Academy of Scientific and Innovative Research (AcSIR) towards seismic hazard mitigation have been comprehensively scrutinised, evaluated and explained in terms of seismic disaster scenario recreation and impact assessment.
\end{abstract}

Keywords: Rapid Visual Screening; Mega Mock Drill Exercise; Scenario Earthquake; CSIR 800; NE India.

\section{Introduction}

Even as the time and space prediction of an earthquake is far from reality, the devastations caused by this natural calamity could be efficiently mitigated and managed through adequate preparedness [Turner et al., 1986; Lehman and Taylor, 1987; Mileti, 1999; Perry et al., 2001 and Ramirez and Peek-Asa, 2005]. In fact, such strategies are globally recognized and promoted for efficiently minimizing the devastations suffered by the affected populace [Banerjee 


\section{Chandan Dey et al.}

and Gillespie, 1994]. Emergence of a high magnitude earthquake event may inflict multifaceted socio-economic distress on a society [Srivastava and Gupta, 2004; Marano et al., 2010 and Khazai et al., 2011]. With an increase in the frequency and intensity of natural disasters [Kostyuchenko and Movchan, 2014], there has been widespread efforts by the authorities in many countries to formulate strategies against such disasters with the aim of saving human lives and loss of property [Takeuchi, 2012; Baytiyeh and Naja, 2013 and Liang and Cao, 2015]. The unpredictability of earthquake impelled authorities to look for hazard mitigation through appropriate interventions, which can contribute significantly in minimizing the impact of earthquake and hence the loses.

The government actions, towards lowering the impact of disasters, are executed overwhelmingly via an architecture involving an assembly of expertised personalities that formulates the decisions for coherent implementation [Renn et al., 2011]. The National Disaster Management Authority (NDMA), Ministry of Home Affairs, Government of India is the nodal agency in the country authorized with the mandate to implement and execute multifield strategies for disaster management. So far as earthquake preparedness is concerned, the agency collaborates and entrusts regional institutions, bestowed with intellect and instrument facilitation, to ubiquitously enforce and implement its policies for disaster management. The Geo Sciences and Technology Division (GSTD) of CSIR-North East Institute of Science and Technology (CSIR-NEIST), Jorhat, Assam, a premiere research and development organization of the NE India region and a constituent laboratory of the Council of Scientific and Industrial Research (CSIR)-New Delhi, India, is adequately equipped with state-of-the-art earthquake research infrastructure and worked jointly with NDMA for several earthquake preparedness campaigns in the region. The division also operated a local seismic network and catalogued several earthquake events originating from the Indian sub-continent.

NE India boasts its uniqueness compared to rest of India primarily due to its geographical isolation from mainland India which led to the evolution of a distinctive geographical entity with a rich political, social, cultural, and historical characteristics and heritage. The region, with an overwhelming and incredible ethnic diversity, probably represents the ethnological transition zone between India and neighbouring China, Bhutan, Burma and Bangladesh [Ali and Das, 2003]. With a total population of 45 million and population density of 174 people per square $\mathrm{km}$ according to 2011 Census of India, the dwellers of NE India are highly vulnerable to earthquakes [Nath et al., 2008] as it is seismically one of the most active regions of the world [Molnar and Tapponnier, 1975; Verma et al., 1976; Krishna and Sanu, 2000 and Kayal, 2008]. Traditional housing practices in the NE India had been dominated by "Kecha Ghar" those are made of bamboo, wood, grass/thatch, mud with roof of tin sheets or asbestos sheets known as Assam-type houses etc (Figure 1). However, the rapid urbanization in the region has led to the construction of high-rise buildings shifting from the conventional Assam-type houses. The latter are relatively safer compared to the modern housing types, given the present burgeoning population and the looming threat from impending large earthquakes. Thus, replacing the traditional housing types has enhanced the proneness of life and property in this region by many degrees to earthquakes and other natural disasters [Thingbaijam et al., 2008]. A brief synopsis of the tectonics and seismicity of NE India as well as its vulnerability to earthquake is mentioned in the succeeding section.

This paper articulates the contribution of the statuary bodies in the NE India region to mitigate seismic hazard. A holistic treatment to the entire gamut of the subject has been presented in the form of scientific scenario and impact assessment. The merit of the study dwells on the fact that deliberations on technological hazards and newer risks dominates in most of the risk governance literatures while the natural hazards find meagre mention [Walker et al., 2010].

\section{Tectonics and Seismicity of NE India}

Several studies have conferred the NE Indian and its adjoining region, including Myanmar, Bhutan and Bangladesh, to be tectonically and seismically very active [Molnar and Tapponnier, 1975; Verma et al., 1976; Ni et al., 1989; Chen and Molnar, 1990; Baruah et al., 1997; Nandy, 2001; Krishna and Sanu, 2000; Kayal, 2008; Baruah et al., 2013; Diehl et al., 2017 and Dey et al., 2021]. It complements to the fact that the region is one of the most complex tectonic provinces in the world [Nandy, 2001; Tiwari, 2002 and Kayal, 2008; Figure 2]. The region is situated in the interaction junction of three major subducting plates viz. the Indian Plate, Sunda Plate and the Eurasian Plate [Angelier and Baruah, 2009]. Convergent plate motion attributes are conveyed by the Eastern Himalayas, the 

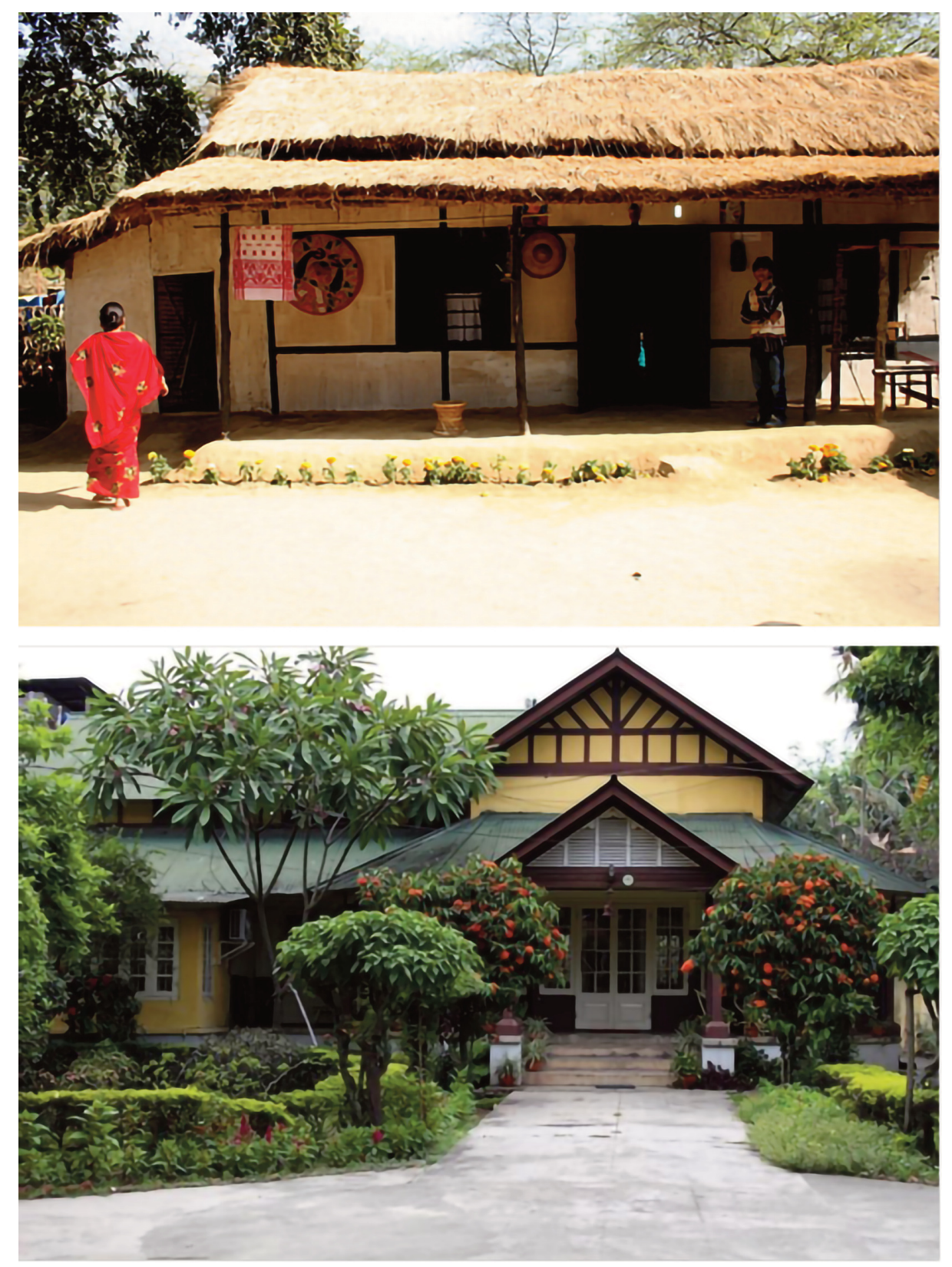

Figure 1. Traditional Assam type houses [OLYMPA, 2014; Hazarika \& Verma, 2017].

eastward extension of the Himalaya, which is considered as the largest orogenic belt of the world [Zhao et al., 1993 and Nandy, 2001], in the north and the Indo-Burma Ranges in the southeast, where subduction activity occurs along the Indo-Burma arc [Mitchell and Mckerrow, 1975, Verma et al., 1976 and Mitchell, 1981]. The Himalayan arc, towards the easternmost margin, interacts with the Burmese arc to form the Assam Syntaxis zone, which is identified as the source area for the 1950 (Ms 8.7) great Assam earthquake [Poddar, 1950; Tillottson, 1953 and Tandon, 1954]. The Shillong and Mikir plateaus, consisting of Precambrian gneiss, granites and the Shillong Group of rocks [Mishra and Sen, 2001], are tectonically active intra plate mounds, characterized by intense seismicity [Kayal and De, 1991; Kayal, 2008 and Dey et al., 2021], flanked to the north by the Assam-Brahmaputra, composed of thick alluvium with few inselbergs of basement rocks [Nandy, 2001]. The northern margin of the Shillong plateau is believed to be the source area of the 1897 (Ms 8.7) great Shillong earthquake [Oldham, 1899]. The Bengal basin, influenced by the rotational behaviour of the converging Indian plate [Khan, 1991], and the Tripura folded belt, a system of narrow and elongated north-south trending folds composed of Tertiary sediments [Alam, 1989], are the other major tectonic domains of the region. 


\section{Chandan Dey et al.}

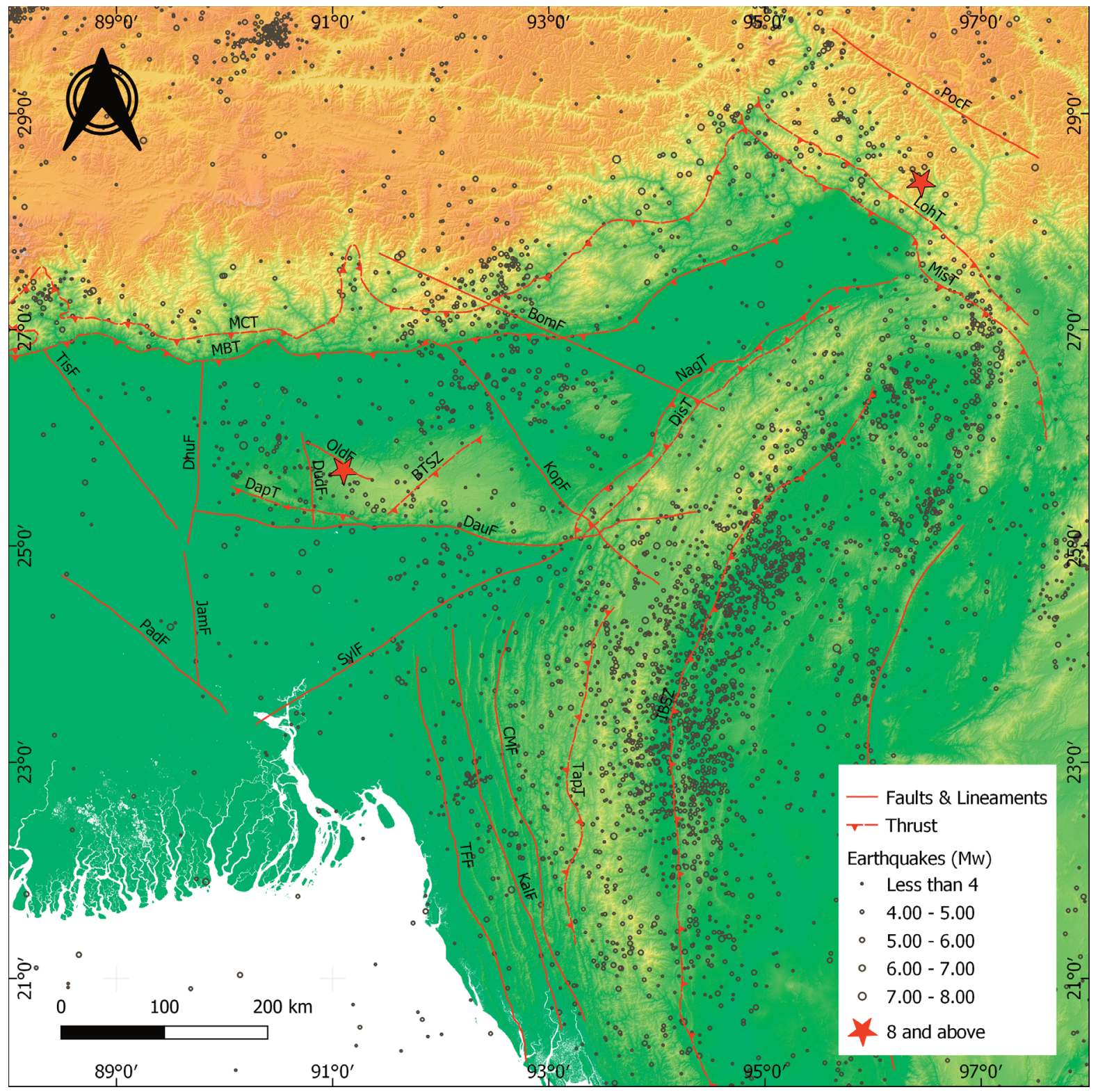

Figure 2. Tectonic map of NE India (modified after Nandy [2001]) showing seismicity [ISC, 2020] of the past 125; the two great earthquakes are show by the stars. (BomF: Bomdila Fault, BTSZ: Barapani-Trysad Shear Zone, CMF: Compressed Mizo Fold; DapF: Dapsi Fault, DauF: Dauki Fault, DhuF: Dhubri Fault, DisT: Disang Thrust, DudF: Dudhnoi Fault, IBSZ: IndoBurma Subduction Zone, JamF: Jamuna Fault, KalF: Kaladana Fault, KopF: Kopili Fault, LohT: Lohit Thrust, MBT: Main Boundary Thrust, MCT: Main Central Thrust, MisT: Mishmi Thrust, NagT: Naga Thrust, OldF: Oldham Fault, PadF: Padma Fault, PocF: Po Chu Fault; SagF: Sagaing Fault, SylF: Sylhet Fault, TapF: Tapu Fault, TFF: Tripura Frontal Fold, TisF: Tista Fault, VolL: Volcanic Line).

During the past 130 years, the region has witnessed at least 22 large ( $M \geqslant 7: 0)$ [Kayal 1996, 2008] and two great earthquakes $\left(\mathrm{M}_{\mathrm{S}} \sim 8: 7\right)$; the older one occurred on 12 June 1897 [Oldham, 1899], and the other on 15 August 1950 [Poddar, 1950; Tillottson, 1953 and Tandon, 1954]. Although, the 1897 great earthquake event was recorded and chronicled by seismic stations outside India, it was the first instrumentally recorded earthquake event of the country [Oldham, 1899]. It prompted the India Meteorological Department (IMD) to establish its first seismic observatory in Alipore (Kolkata) in 1899 [Kayal, 2008]. Subsequently, the 1950 great earthquake was distinctly recorded by the national (IMD) seismic network and by the global seismic stations [Tandon, 1954]. The 1897 great earthquake is argued to have originated due to 'pop-up' tectonics between Dauki fault and Oldham fault influencing the Shillong 
plateau [Bilham and England, 2001], while the 1950 great earthquake is believed to have originated from the Po Chu fault of the Assam syntaxis zone [Ben-Menahem et al., 1974]. Bilham and England [2001] associates the Great Earthquake of 1897 with the 'pop-up' tectonics between the Dauki fault and the Oldham fault in the Shillong plateau. The Great Earthquake of 1950 is believed to have originated from right lateral shear movement along the Po Chu fault [Ben-Menahem et al., 1974]. Some of the other notable historic earthquakes in the region are shown in Table 1 in chronological order. Seismicity of the region for past 125 years is shown in Figure 2.

\begin{tabular}{|c|c|c|c|}
\hline Place & Year & Magnitude & Description \\
\hline Cachar & 1869 & 7.4 & $\begin{array}{l}\text { Buildings were damaged; land fissures, liquefaction and sand } \\
\text { venting }\end{array}$ \\
\hline Shillong & 1897 & 8.7 & Shillong city was devastated with more than 1600 fatalities \\
\hline Srimangal & 1918 & 7.6 & Buildings damaged \\
\hline Dhubri & 1930 & 7.1 & Old constructions were damaged; no loss of life reported \\
\hline Assam & 1943 & 7.2 & The entire region shook \\
\hline Assam & 1950 & 8.7 & $\begin{array}{l}\text { Widespread devastations felt across Assam valley with land } \\
\text { fissures, landslides, liquefaction, reversal of stream flow direction. } \\
\text { About } 1,526 \text { fatalities reported. }\end{array}$ \\
\hline Manipur & 1988 & 7.2 & The entire region shook \\
\hline
\end{tabular}

Table 1. Occurrence of some notable earthquake events in the NE India (modified after Thingbaijam et al. [2008]).

According to the practice of Indian standard code for earthquake resilient design of structures, the region is classified under Zone $\mathrm{V}$ of the seismic zonation map of India (Figure 3), which is seismically reckoned as the most hazardous zone [Indian Standard, 2002]. Simultaneously, the region is categorized under Zone IV, i.e. very high seismic risk zone with peak ground acceleration of about $0.35-0.4 \mathrm{~g}$, by the Global Seismic Hazard Assessment Programme carried out in India by the National Geophysical Research Institute, Hyderabad [Bhatia et al. 1999]. A number of earthquake recurrence studies have also been carried out in the region; the recurrence probability of $\mathrm{M}_{\mathrm{W}} \geqslant 7$ earthquake is modelled to be 13-20 years [Yadav et al., 2010] and that for $\mathrm{M}_{\mathrm{W}} \geqslant 5$ is found to be 140 days [Chetia et al., 2019]. Return period and occurrence probability study for the region indicates that the most probable largest magnitude annual earthquake is about 5.8 [Yadav et al., 2011].

\section{Activities undertaken}

The toll of lives and damage of properties incurred due to an earthquake are critical to disaster mitigation preparedness, emergency management, rescue and restoration. Evaluation of non-structural mitigation practices is an important aspect of earthquake disaster awareness. Therefore, CSIR NEIST and NDMA, apart from its regular awareness dispensation programs, holistically envisaged a comprehensive preparedness, awareness and perception program constituting two major components, viz. (i) to create a scientific scenario of loss and damage for the event of recurrence of the M 8.7 Shillong Plateau earthquake, based on the historically recorded intensities of ground shaking observed during 1897, and (ii) to make the masses aware about the hazardous situation and encourage earthquake preparedness through media campaign, well organized road shows, workshops on capacity development, school children sensitization and Mock drills [CSIR-NEIST, 2016]. 


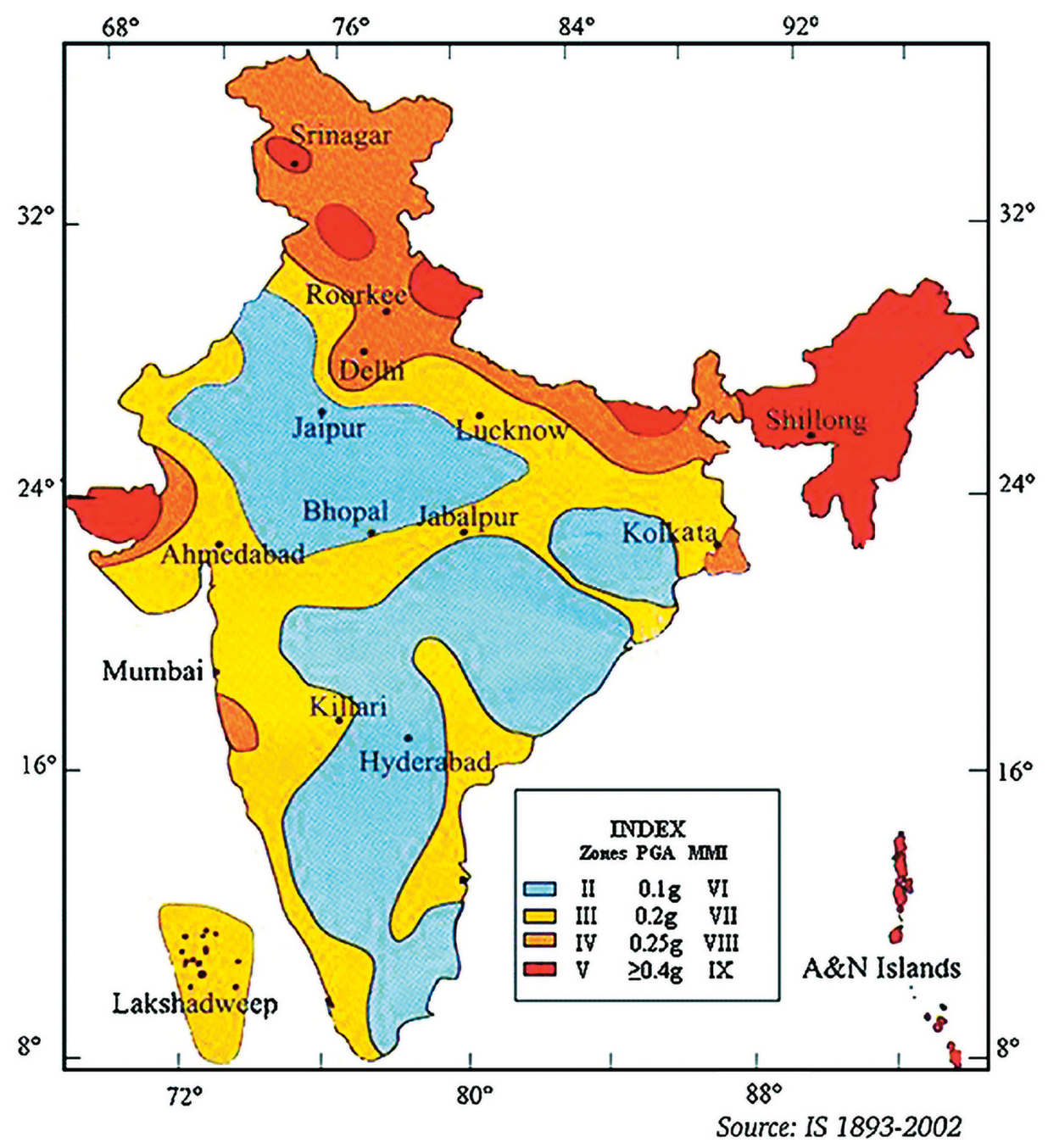

Figure 3. Seismic zonation map of India [Indian Standard, 2002; Verma et al., 2014], indicating the four seismic hazard zones starting from Zone II, implying low hazard with 0.1 PGA, to Zone V, implying very high hazard with more than 0.4 PGA.

\subsection{Mega Mock Drill Exercise}

To generate awareness among the people, NDMA in coordination with the SDMAs (State Disaster Management Authority) conducted Mega Mock Exercises, in at least two districts of all the states in NE India, to prepare the first time responders to experience and ready themselves to face any such unusual situation in the future. The NDMA periodically conducts such Mega Mock Exercises in the seismically active cities of the country. Such exercise helps in understanding the direct and indirect repercussions of a big earthquake with an assessment of contemporary preparedness [Sharma et al., 2014]. Apart from generating awareness, it also helps in identifying gaps after evaluating disaster management plans and inter-departmental coordination.

A series of preparatory assembly involving eminent intellects, state government representatives, and stake holders with brainstorming sessions preluded the exercises. During these meetings the venue and time for conducting the exercises were decided. Prior to mega mock exercise, the NDMA also conducted several capacity development programs to explicate the role and duty of all the stakeholders and synergize their coordination, while identifying the lapses and vulnerable groups. It also includes extensive media sensitization workshops for publicity and advertisement in local language to enhance the outreach. Finally, mega mock exercises were conducted in more than 80 locations with a hypothetical earthquake scenario of magnitude 8.7 and focal depth of 15-18 km, developed by CSIR NEIST imitating the damage and devastation of the great Shillong 1897 earthquake, in two phases (Figure 

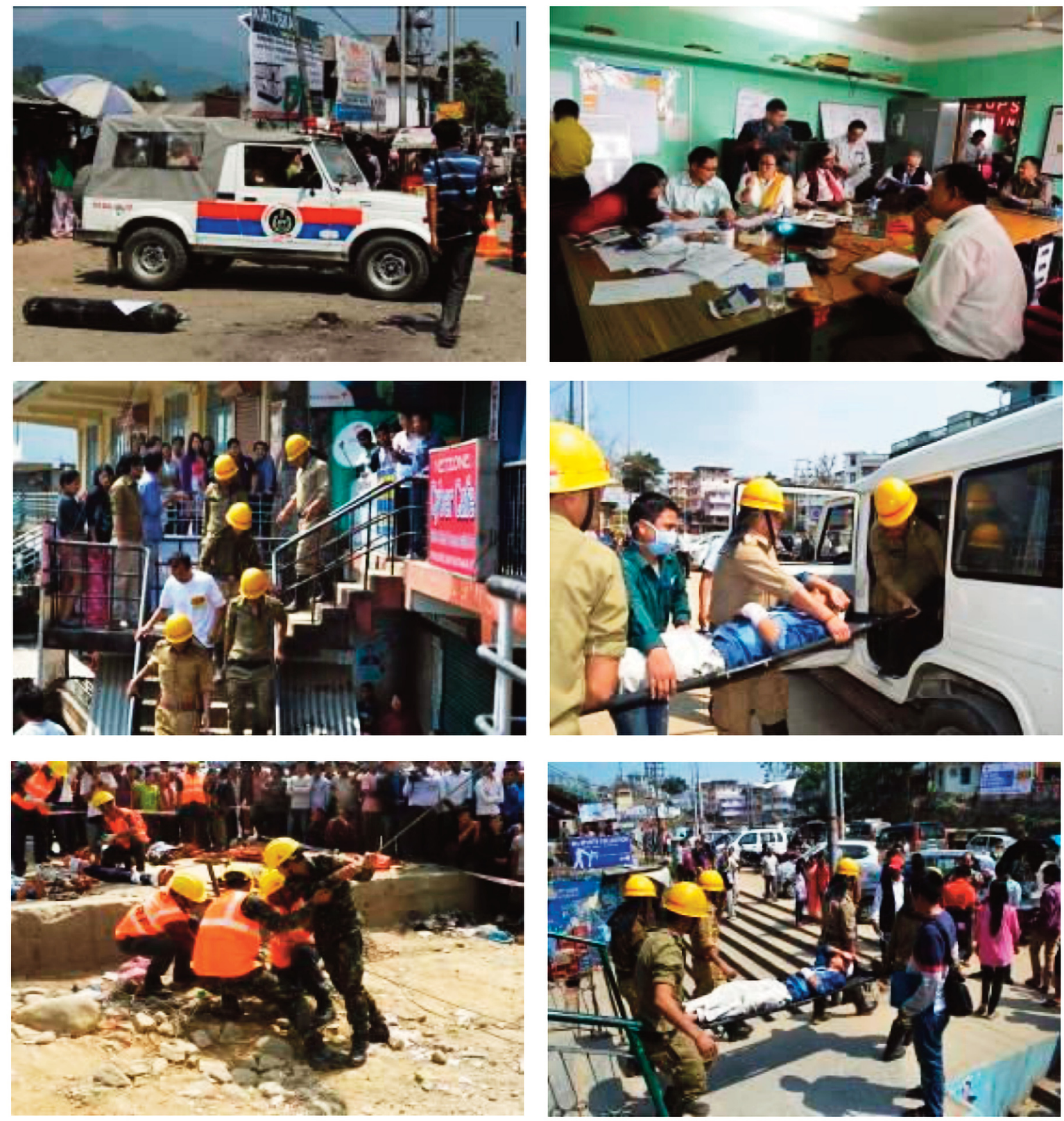

Figure 4. Glimpse of several activities undertaken during the mega mock exercise at one of the locations [CSIR-NEIST, 2016].

4). Phase I, covering the states of Assam, Arunachal Pradesh, Meghalaya and Sikkim, was conducted on 10th March, 2014 and Phase II, covering the states of Nagaland, Manipur, Tripura and Mizoram, was carried out on 13th March, 2014. Apart from the respective SDMAs, Fire Service, Police Forces, Medical Service, Transport Service, Telecommunication department, State Electricity Board, Army, Home guards and Civil Defence Volunteers were part of the exercises [CSIR-NEIST, 2016].

The important observations from the mega mock drill exercise are: (1) Almost all the NE States lack modern and $24 \times 7$ hours functional emergency operation centres with robust communication facility. (2) Disaster management plans for most of the districts are not ready or finalized with incomplete resource inventories. (3) Fire and Emergency Services are not adequately armed and lack basic disaster management equipment like mist technology, foam tenders, saws for cutting concrete, wood drillers and high-rise ladders etc. Vulnerability assessment of lifeline buildings and critical infrastructure, in the form of rapid visual screening, was recommended. On the hindsight, successful operation of the exercises indicated efficient inter-departmental cooperation for replication in real scenarios [CSIR-NEIST, 2016]. 


\section{Chandan Dey et al.}

\subsection{Training on Rapid Visual Screening}

Rapid Visual Screening (RVS) is a simple, robust and cost-effective preliminary technique, with high degree of applicability, for examining the structural resilience of building for further necessary assessment [Jain et al., 2010]. However, such visual information alone cannot be used as intervention to reduce seismic vulnerability of buildings [Sinha and Goyal, 2004]. Implementation of the RVS technique helps in generating first-hand information about the seismic vulnerability of a building. The data can be highly useful in formulating safety measures for the lifeline structures and vitally assist in post-earthquake emergency management [CSIR-NEIST, 2016].

RVS training program was imparted to participants, comprising of Civil Engineers, Architects, Geologists and Administrators, by domain experts from NDMA in major cities of all the NE Indian states (Figure 5). After the theoretical and technical sessions, the trainees, in multiple groups, were taken to important lifeline buildings, to impart knowledge on codal specifications of the buildings. Hands-on training on earthquake vulnerability assessment based on recommended RVS guidelines by studying the wall types, foundation design, availability of seismic resistant structures, dimensions of various openings, walls, size and position of beams and column, identifying falling hazards and non-structural components etc were provided. Upon completion of the training, the trainees developed satisfactory understanding to judge the buildings, and deliver a grade of likely damageability following RVS criteria [CSIR-NEIST, 2016].

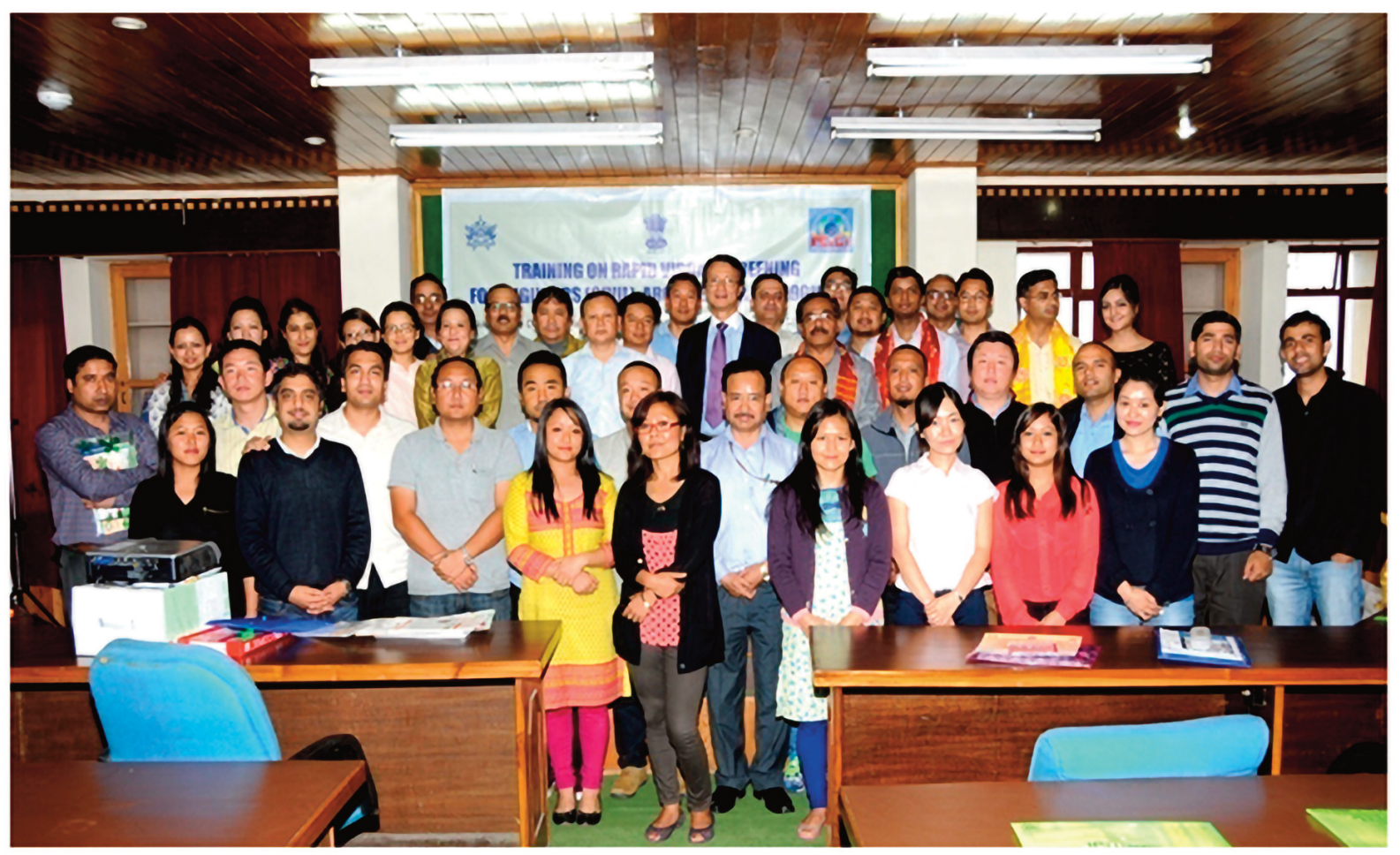

Figure 5. Photograph showing Participants and Resource person of Rapid Visual Training conducted at Gangtok, Sikkim [CSIR-NEIST, 2016].

\subsection{School Children Sensitizing Workshop}

The education and training availed by the students in their school plays a major role in developing tangible cognizable perception [Radu, 1993; Kuroiwa, 1993 and Lidstone, 1999]. Extensive school children sensitization workshops were carried out addressing large gathering of school children in all the state capitals of NE India by eminent geoscientists from the country, to make them aware about the fatal consequences of seismic hazards (Figure 6). The workshops were carried out with the aim of imparting interactive education on Earth Science and earthquake 
hazard, including simplified guidelines of basic mitigation and preparedness measures to adopt before and after an earthquake event. Widespread generation of awareness and its optimum outreach was envisaged through these workshops by educating the children about the seismic history of the region, and the havocs caused by the great earthquakes, with a brief idea about the tectonic setting. Audio-visual sessions and practical demonstrations on first aid, search and rescue related operations were also performed [CSIR-NEIST, 2016].

Besides, the PhD researchers of GSTD, CSIR NEIST, registered under the AcSIR, are entrusted with societal projects under the aegis of which earthquake sensitization of the rural tea belt school children is regularly carried out (Figure 7). Assam is the single largest tea cultivating region in the world, constituting nearly $57 \%$ of India's total tea consumption [Tea Board of India, 2017] and growing some of the world's premium black tea [FAO, 2016]. The AcSIR curriculum mandates its PhD students to pursue the CSIR-800 Program, which is a credit-based project of about 2 months concerning with the societal and rural issues, to nurture human resources capable of acculturating research in science and technology with a conscientious bearing on social economic, cultural, intellectual and academic prosperousness of the people.
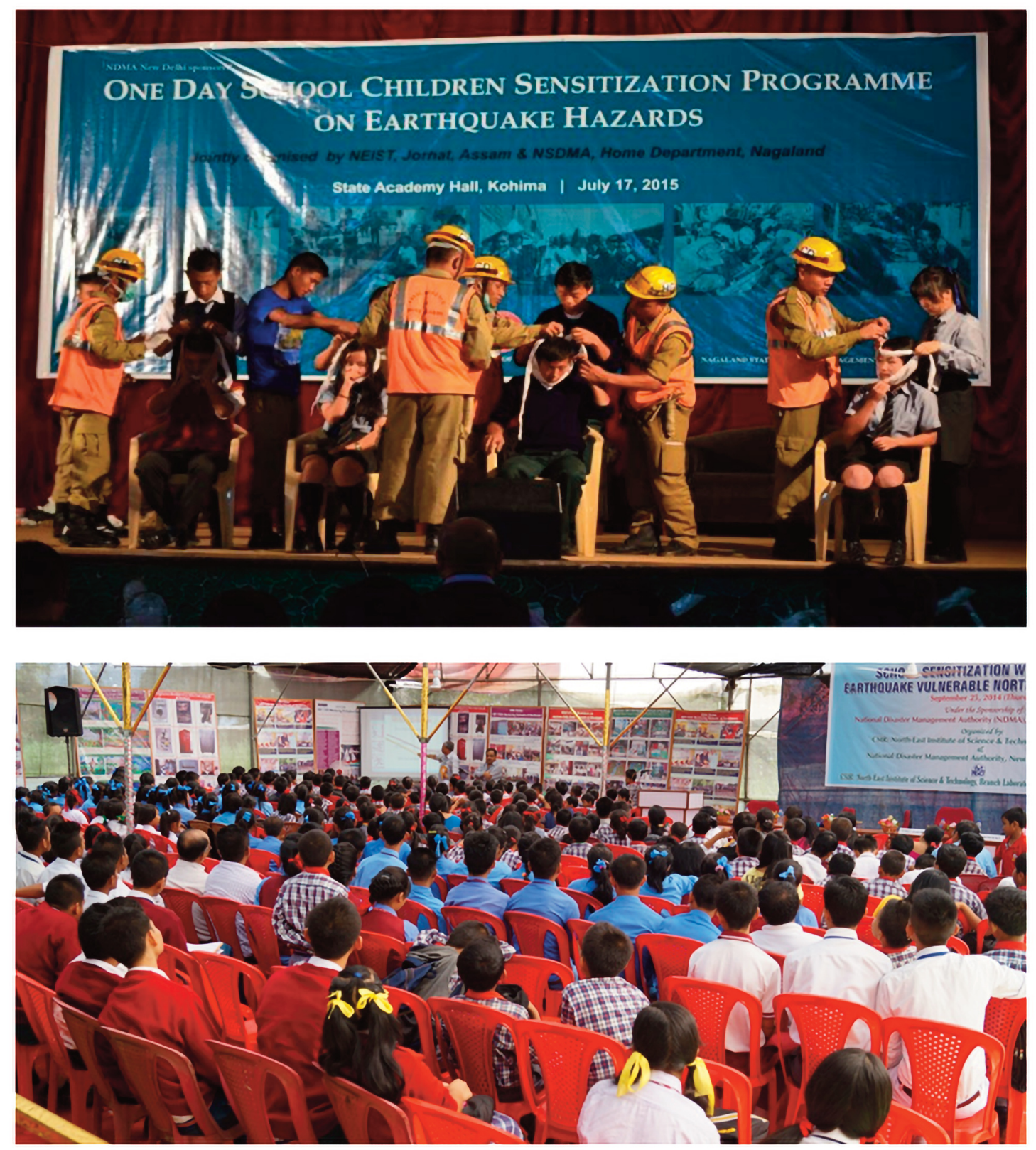

Figure 6. Photographs of school children sensitization workshop [CSIR-NEIST, 2016]. 

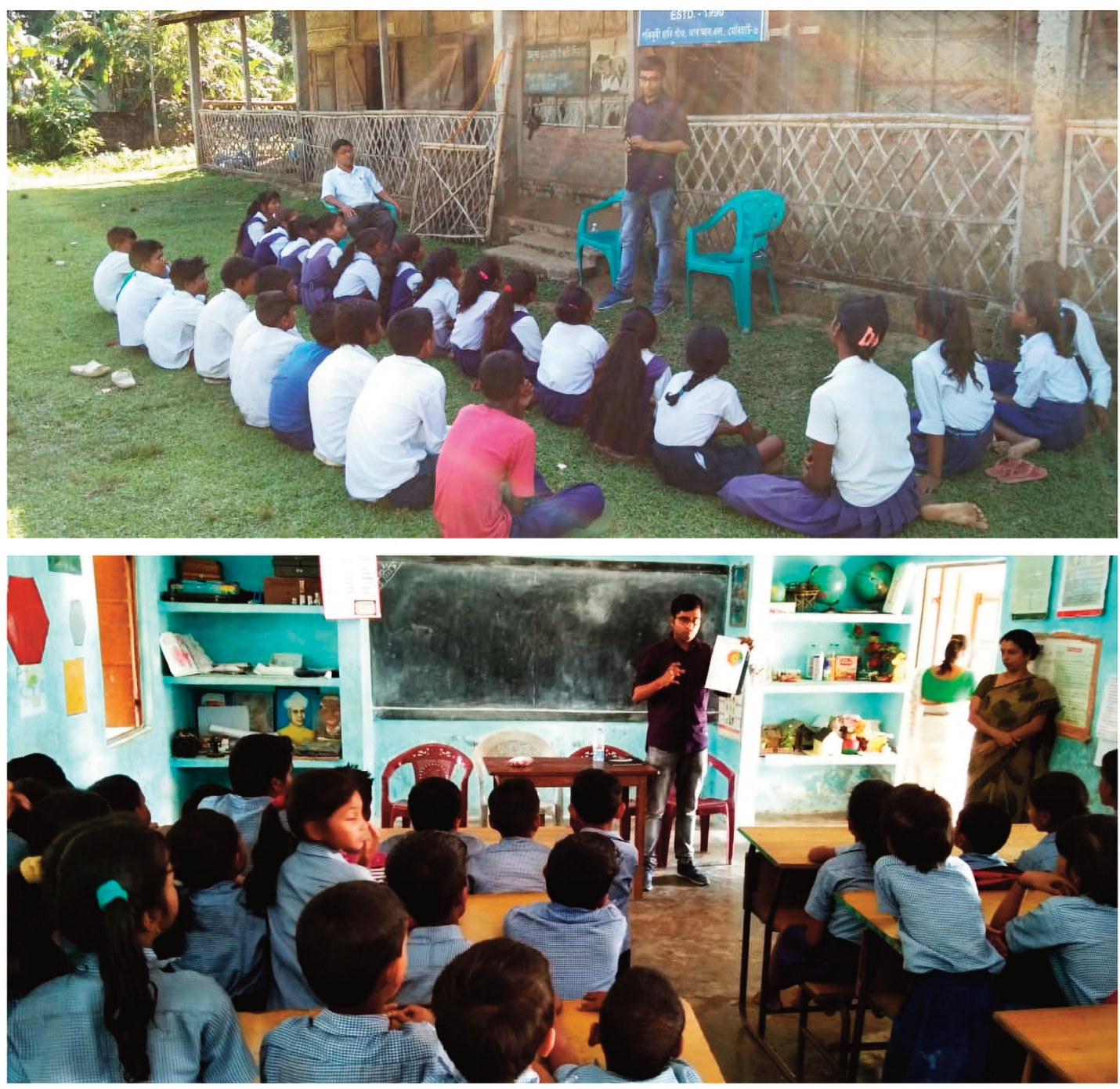

Figure 7. Photograph of societal project undertaken by PhD student of CSIR NEIST registered under AcSIR to create awareness amongst the rural tea belt school children of Assam.

\subsection{Earthquake Scenario Exercise}

Simulating scenario of a previously triggered devastating earthquake helps in developing appropriate emergency response parameters while creating inferences on risk reduction measures [Bommer et al, 2000]. The scenario of the Ms 8.7, great Shillong earthquake of 1897 was simulated, considering the scale and magnitude of historical devastation attributed to the event, for the present-day dispensation. The earthquake was believed to have been triggered by the Eastern Himalayan tectonics [Seeber et al., 1981: Molnar, 1988 and Gahalaut and Chander, 1992], however, recent studies have prescribed an intra-plate mechanism [Bilham and England, 2001]. Some of the important parameters for developing the scenario involved building types, local soil characteristics, population characteristics, lifeline structures and up-to-date social, scientific and engineering information of historical earthquakes for the region. GIS based software platform was used for incorporating the parameters and developing scenario models [CSIR-NEIST, 2016].

The results indicate that the region encompassed by highest intensity zone, i.e. VIII - IX of MedvedevSponheuer-Karnik scale, are East Garo Hills, South Garo Hills and West Khasi Hills districts of Meghalaya and Kamrup district of Assam, including two important cities of Guwahati and Shillong and significantly affecting a collective population of about 2.36 million. Such estimates were also calculated for lower intensity scale zones. It 
was observed that the states of Nagaland, Mizoram \& Arunachal Pradesh are relatively better prepared in terms of building typology, as most of the states have traditional wooden houses, to face such earthquake. While Tripura and Manipur are characterized by a good number of mud-houses constructed with large un-burnt bricks with mud mortars. These houses are quite vulnerable to earthquake ground motion [CSIR-NEIST, 2016]. It was concluded that such scenarios could provide extremely effective tools to improve the general understanding of earthquakes. Such scenarios also offer prospects for examining alternative opportunities and stimulate creative contemplation on the needs for innovative policies and programs.

\subsection{Media Sensitization Campaign}

The role of media for generation of earthquake awareness is monumental [Tekeli-Yeşil et al., 2014]. A series of media sensitization workshops were held which were convened by distinguished representatives of SDMA, NDMA and CSIR NEIST with the prime agenda of disseminating earthquake awareness information and encourage its mitigation preparedness. Audio-visual awareness generation campaigns were conducted in local language, apart from English, to achieve widespread coverage involving the national public broadcasting channels with the help of tagline slogans. Specially programmed, talk shows were also aired via TV networks to generate awareness on earthquake and highlighting the importance of preparedness. Pamphlet and brochures, designed by NDMA, were extensively distributed to the people, and also circulated in the form multilingual newspaper advertisements. Apart from it, poster, guide and calendar with awareness information were distributed [CSIR-NEIST, 2016].

\section{Assessment of the activities undertaken}

A realistic assessment of community earthquake awareness exercise involves meticulous observation of cognitive and behavioural development of the target audience in terms of knowledge and skills acquired and its efficient implementation during the event of an earthquake. Several assessment techniques are prescribed, by previous researchers, from observing knowledge and behavioural attributes after a suitable period of time [Karanci et al., 2005] to development of a tool for accessing earthquake risk communication [Platt et al., 2017]. Precise and sophisticated implementation of earthquake awareness with methodical interaction at schools, for instance the 'Situated Learning Episode’ under the KnowRISK project [Musacchio et al., 2017], are highly feasible for assessing the orderly progress in cognizant learning and adaptability.

The activities undertaken by the said nodal agencies in NE India, however, are multifaceted and targets a broad range of audience. It is imperative to mention that these practices are largely inspired by the global trend to shift towards integrated earthquake awareness programs and most of the exercises were implemented for the first time in NE India. Therefore, the indices to gauge the enhancement of general earthquake awareness were conditioned and limited. To derive a preliminary idea of the impacts of the awareness exercises, the mega mock drill events were preceded by a series of capacity development programs, well organized road shows, media campaigns, where NDMA approved earthquake awareness and preparedness brochures were published through local newspapers and such pamphlets were extensively distributed. Mass communication media viz. FM Radio and SMS alert, community radio etc. were utilized to the optimum for larger dissemination of information regarding the mock drill and pre-mega mock exercises. The capacity development program included simulation of incident response system, tabletop exercise and rapid visual screening of buildings and structures. The widespread publicity of the mega mock drill exercise and earthquake awareness and preparedness information culminated with successful conduction of the mega mock drill exercises at 80 different locations in NE India. The robust and efficient participation of the people, including the systematic cooperation between the different stakeholders, suggest a satisfactory degree of sensitization amongst the participating mass.

The school children sensitization workshops were mostly held at a common gathering hall addressing an audience comprising of children, parents and teachers from several schools. Although, the workshops were highly interactive with rigorous question and answer sessions, no formal assessment activities were carried out. As these workshops were carried out furnishing audio-video explanations on earthquake preparation process to its occurrence in the background of the regional tectonics and seismology, apart from imparting basic earthquake 


\section{Chandan Dey et al.}

awareness and preparedness guidelines, the students were visibly enthusiastic and their proactive participation in question and answer sessions indicated tangible development in their perception about earthquakes and its preparedness. Besides, the earthquake awareness societal projects carried out by the PhD researchers at CSIR NEIST, involve one-to-one interaction and questionnaires to access the improvement in cognitive understanding and behavioural traits. It is observed that the students in the urban schools are highly aware and prepared about earthquakes and pre and post assessment scores were mostly above $80 \%$ and had narrow gaps. However, the rural, government run, school students had limited perception on earthquake preparedness. With adequate training and drills, the post assessment scores were impressively high ranging beyond $70 \%$.

The scenario exercises estimated the loss and damage that may be caused by a great earthquake which primarily were destruction of property, infrastructure, crops, temporary unemployment, business loss and social chaos, etc [CSIR-NEIST, 2016]. RVS trainees were tasked to carry out screening of a sizeable sample of buildings which were meticulously examined by experts and found to be adequately skilled in performing it and in the aftermath integrated seismic vulnerability studies were extensively carried out in NE India [Baruah et al., 2019]. Media sensitization programs were carried out via newspaper and television channels in local languages under the aegis of national experts and therefore it is safe to estimate that the concept of earthquake awareness and preparedness was meaningfully introduced and its perceptible rise in NE India was imminent. However, there were no adequate means to statistically derive the footprints and reach of these programs.

\section{Conclusion}

The study attempts to compile the multi-disciplinary awareness programme, in the form of preparedness for mitigation and optimum dissemination of scientific information primarily concerned with the non-structural components, practiced by the nodal governmental institutes of NE India - seismically one of the most vulnerable regions of the country. The approach ought to be appreciated considering the economic constraints of a developing country like India. The efforts aim in inducing and inculcating a collective sense of 'earthquake culture' to familiarize the vulnerable population of the entire region with the regular dispensations of an earthquake and encourage resilient practices so as to 'live with earthquakes'. The duty and responsibility of the emergency services and their coordination with different departments should significantly improve. However, to harness the success achieved as a result of the activities undertaken, the agencies should frequently carry out the said operations. The tasks that involve minimum expenditure may be carried out more frequently, for example once at least in six months, than the mega mock drill exercises. The agencies should encourage school authorities to incorporate earthquake awareness activities into the academic curriculum [Baruah et al., 2020].

The initial step, involving an all-inclusive and multi-approach earthquake awareness and preparedness campaign, is certainly a huge leap towards developing an earthquake resilient society. It is imperative on the nodal agencies to further this mission by inculcating contemporary global techniques and methodologies, such as region and demography specific applications [De Lucia et al., 2020], and formulate adequate parameters to assess the positive impacts. Educational institutes are of paramount importance when it comes to disseminating a majority of awareness and preparedness activities, therefore, it is further prescribed to adopt highly intuitive techniques, involving hands on tools, emotion-driven, curiosity-driven and learn-by-playing approach [Musacchio et al., 2016; Piangiamore et al., 2015], with frequent and intensive observation.

However, the fact remains that occurrence of an earthquake akin to the, Ms 8.7, great Shillong earthquake in the present-day context would create an intensely damaging scenario chiefly due to the rapid outburst of population and haphazard urbanization with poor engineering design of most of the building constructions. The loopholes and gaps identified by the exercises, such as availability of disaster management plan, upgradation of emergency operation centre and empowering emergency service bodies with robust instrumentation facility, should be attended urgently. Mock drill exercises should be regularly conducted in school, hospital and other such institutes, while unsafe buildings of critical lifeline importance, should be retrofitted. The competent authorities should holistically consult with the nodal agencies and the experts involved in identifying the loopholes to mandate quick and viable solutions to the prevalent situation and means to ameliorate these critical facilities. Apart from few machinery upgradations for the disaster task forces, no discernible steps have been taken by the competent authorities to iron out the core issues. Assam in NE 
India, being one of the most flood affected regions of the country incurs sizeable disaster management expenditure, which may be a probable reason for the ambiguous and disinclined attention in fixing the issues.

Acknowledgment. We thank Dr. G N Sastry, Director, CSIR-North East Institute of Science and Technology (CSIR-NEIST), Jorhat, for his kind support and encouragement in carrying out this work. We offer our heartfelt acknowledgement to Dr. Saurabh Baruah, Chief Scientist, CSIR-NEIST for his encouragement and guidance. The author MKP acknowledge the financial support from NDMA, Govt of India, New Delhi, Grant No. NDMA 5-36/2013-Mit dated 21/11/2013. We thank the implementing team of the NDMA sponsored program as well as all the State Govts. of NE India for their active cooperation. Special thanks to Dr. Ranju Duarah, Chief Scientist (Retd.), CSIR-NEIST for his active role in the programme and encouragement. The author SB acknowledges Science \& Engineering Research Board (SERB), Government of India for the MATRICS Scheme, vide Sanction No. MTR/2019/000074.

\section{References}

Alam, M. (1989). Geology and depositional history of Cenozoic sediments of the Bengal Basin of Bangladesh, Palaeogeol., Palaeoclim., Palaeoecol., 69, 125-139.

Ali, A.I. and I. Das (2003). Tribal situation in north east India, Studies of Tribes and Tribals, 1, 2, 141-148.

Angelier, J. and S. Baruah (2009). Seismotectonics in Northeast India: a stress analysis of focal mechanism solutions of earthquakes and its kinematic implications, Geophys. J. Int., 178, 1, 303-326.

Banerjee, M.M. and D.F. Gillespie (1994). Linking disaster preparedness and organizational response effectiveness, J. Community Pract., 1, 3, 129-142.

Baruah, S., R. Duarah and D.K. Yadav (1997). Pattern of Seismicity of Shillong-Mikir Plateau and the Orientation of Compressional Axis, J. Geol. Soc. India, 49, 533-538.

Baruah, S., S. Baruah and J.R. Kayal (2013). State of tectonic stress in Northeast India and adjoining South Asia region: an appraisal, Bull. Seismol. Soc. Am., 103, 2A, 894-910.

Baruah, S., G.K. Boruah, S. Sharma, W.A. Hoque, T. Chetia, C. Dey, D. Gogoi, P.K. Das, S. Baruah, D. Basumatari and J. Pathak (2020). Seismic vulnerability assessment of earthquake-prone mega-city Shillong, India using geophysical mapping and remote sensing, Georisk: Assessment and Management of Risk for Engineered Systems and Geohazards, 14(2), 112-127.

Baruah, S., C. Dey, G.N. Sastry and A.J. Michael (2020). Global seismology and tectonics, Current Science, 119, 12, 1885-1887.

Baytiyeh, H. and M. Naja (2013). Promoting earthquake disaster mitigation in Lebanon through civic engagement, Disaster Prev. Manag., 22(4), 340.

Ben-Menahem, A., E. Aboodi and R. Schild (1974). The source of the great Assam earthquake-an interplate wedge motion, Phys. Earth Planet. Inter., 9(4), 265-289.

Bhatia, S. C., M.R. Kumar and H.K. Gupta (1999). A probabilistic seismic hazard map of India and adjoining regions, Ann. Geophys., 42, 6, 1153-1164.

Biggs, E.M., N. Gupta, S.D. Saikia and J.M. Duncan (2018). The tea landscape of Assam: multi-stakeholder insights into sustainable livelihoods under a changing climate, Environ. Sci. Policy, 82, 9-18.

Bilham, R. and P. England (2001). Plateau 'pop-up' in the great 1897 Assam earthquake, Nature, 410, 6830, 806-809.

Bommer, J.J., S.G. Scott and S.K. Sarma (2000). Hazard-consistent earthquake scenarios, Soil Dyn. Earthq. Engin., 19(4), 219-231.

Chen, W.P. and P. Molnar (1990). Source parameters of earthquakes and intraplate deformation beneath the Shillong Plateau and the northern Indoburman ranges, J. Geophys. Res.: Solid Earth, 95, B8, 12527-12552.

Chetia, T., S. Baruah, C. Dey, S. Sharma and S. Baruah (2019). Probabilistic analysis of seismic data for earthquake forecast in North East India and its vicinity, Current Sci., 117, 7, 1167-1173.

CSIR-NEIST (2016). Final Report on "M 8.7 Shillong 1897 Earthquake Scenario: NE Multi-State Preparedness Campaign” (NDMA New Delhi Sponsored \& Guided Program), Grant No. NDMA 5-36/2013-Mit, dated 21/11/2013, CSIR - North East Institute of Science and Technology, Jorhat, 1-348

De Lucia, M., F. Benassi, F. Meroni, G. Musacchio, N.A. Pino and S. Strozza (2020). Seismic disasters and the 


\section{Chandan Dey et al.}

demographic perspective: 1968, Belice and 1980, Irpinia-Basilicata (southern Italy) case studies, Annals of Geophysics, 63, 1, SE107.

Dey, C., S. Baruah, G. Rawat, T. Chetia, S. Baruah and S. Sharma (2021). Appraisal of contemporaneous application of polarization ratio and fractal analysis for studying possible seismo-electromagnetic emissions during an intense phase of seismicity in and around Assam Valley and the Eastern Himalayas, India, Phys. Earth Planet. Int., 318, 106759.

Diehl, T., J. Singer, G. Hetényi, D. Grujic, J. Clinton, D. Giardini, E. Kissling and GANSSER Working Group (2017). Seismotectonics of Bhutan: Evidence for segmentation of the Eastern Himalayas and link to foreland deformation, Earth Planet. Sci. Lett., 471, 54-64.

FAO (2016). Report of the Working Group on Climate Change of the FAO Intergovernmental Group on Tea, Food and Agriculture Organization of the United Nations, Rome, 1-100.

Gahalaut, V.K. and R. Chander (1992). On the active tectonics of the Dehra Dun region from observations of ground elevation changes, J. Geol. Soc. India, 39, 61-68.

Hazarika, K and G. Verma (2017). The Assam-type Houses that take us on a trip down nostalgia lane. (https://www.nezine.com/info/OHE3alZQbzFXK3VIdjUwRWtoOERPZz09/the-assam-type-houses-that-takeus-on-a-trip-down-nostalgia-lane.html), Accessed: 2021-06-24

Indian Standard, I.S. (2002). Criteria for earthquake resistant design of structures, Bureau of Indian Standards, New Delhi, 1-24

International Seismological Centre, I.S.C. (2020). On-line Bulletin.

Jain, S.K., H. Mitra, M. Kumar and M. Shah (2010). A proposed rapid visual screening procedure for seismic evaluation of RC-frame buildings in India, Earthquake Spectra, 26, 3,709-729.

Khazai, B., J. Daniell and F. Wenzel (2011). The March 2011 Japan earthquake, TATuP-Zeitschrift für Technikfolgenabschätzung in Theorie und Praxis, 20, 3, 22-33.

Kostyuchenko, Y. and D. Movchan (2014). Risk Perception as the Quantitative Parameter of Ethics and Responsibility in Disaster Study. In EGU General Assembly Conference Abstracts, 16, 831.

Karanci, A.N., B. Aksit and G. Dirik (2005). Impact of a community disaster awareness training program in Turkey: Does it influence hazard-related cognitions and preparedness behaviors, Social Behavior and Personality: an international journal, 33, 3, 243-258.

Kayal, J.R. (1996). Earthquake source process in Northeast India: a review, J. Himalayan Geol., 17, 53-69.

Kayal, J.R. (2008). Microearthquake seismology and seismotectonics of South Asia, Springer Science and Business Media, Springer Netherlands, 1-503.

Kayal, J.R. and R. De (1991). Microseismicity and tectonics in northeast India, Bull. Seismol. S. Am., 81, 1, 131-138.

Khan, A.A. (1991). Tectonics of the Bengal basin, J. Himalayan Geol., 2, 1, 91-101.

Krishna, M.R. and T.D. Sanu (2000). Seismotectonics and rates of active crustal deformation in the Burmese arc and adjacent regions, J. Geodyn., 30, 4, 401-421.

Kuroiwa, J.A. (1993). “Peru's National Educational Program for Disaster Prevention and Mitigation (PNEPDPM).” In Training and Education for Improving Earthquake Disaster Management in Developing Countries. Report and Summary of Proceedings of the Sixth International Research and Training Seminar on Regional Development Planning for Disaster Prevention, Tsukuba, Japan, 14 December 1992, 95-102.

Lehman, D.R. and S.E. Taylor (1987). Date with an earthquake: Coping with a probable, unpredictable disaster, Personality Social Psychol. Bull., 13, 4, 546-555.

Liang, Y. and R. Cao (2015). Employment assistance policies of Chinese government play positive roles! The impact of post-earthquake employment assistance policies on the health-related quality of life of Chinese earthquake populations, Social Indicators Res., 120, 3, 835-857.

Lidstone, J. (1999). Disaster education in the school curriculum, Natural Disaster Management, Tudor Rose, Leicester, UK, 235-245.

Marano, K.D., D.J Wald and T.I. Allen (2010). Global earthquake casualties due to secondary effects: a quantitative analysis for improving rapid loss analyses, Nat. Hazards, 52, 2, 319-328.

Mileti, D. (1999). Disasters by design: A reassessment of natural hazards in the United States, Washington, DC, Joseph Henry Press, 1-371.

Mishra, U.K. and S. Sen (2001). Dinosaur bones from Meghalaya, Current Sci., 80, 8, 1053-1056.

Mitchell, A.H.G. (1981). Phanerozoic plate boundaries in mainland SE Asia, the Himalayas and Tibet, J. Geological 
Soc., 138, 2, 109-122.

Mitchell, A.H.G. and W.S. McKerrow (1975). Analogous evolution of the Burma orogen and the Scottish Caledonides, Geol. Soc. Am. Bull., 86, 3, 305-315.

Molnar, P. (1988). A review of geophysical constraints on the deep structure of the Tibetan Plateau, the Himalaya and the Karakoram, and their tectonic implications, Philosophical Transactions of the Royal Society of London, Series A, Mathematical and Physical Sciences, 326, 1589, 33-88.

Molnar, P. and P. Tapponnier (1975). Cenozoic tectonics of Asia: effects of a continental collision, Science, 189, 4201, 419-426.

Musacchio, G., S. Falsaperla, A.E. Bernhardsdóttir, M.A. Ferreira, M.L. Sousa, A. Carvalho, and G. Zonno (2016). Education: Can a bottom-up strategy help for earthquake disaster prevention?, Bull. Earthq. Engin., 14,7, 2069-2086.

Musacchio, G., E. Eva and G.L. Piangiamore (2018). The KnowRISK Action for Schools: A Case Study in Italy, In Proceedings of the International Conference on Earthquake Engineering and Structural Dynamics, Springer, 47, 459.

Nandy, D.R. (2001). Geodynamics of northeastern India and the adjoining region, ACB Publication, Calcutta, 1-209.

Nath, S.K., K.K.S Thingbaijam, and A. Raj (2008). Earthquake hazard in northeast India-a seismic microzonation approach with typical case studies from Sikkim Himalaya and Guwahati city, J. Earth Sys. Sci., 117, 2, 809-831.

Ni, J.F., M. Guzman-Speziale, M. Bevis, W.E. Holt, T.C. Wallace and W.R. Seager (1989). Accretionary tectonics of Burma and the three-dimensional geometry of the Burma subduction zone, Geology, 17, 1, 68-71.

Oldham, R.D. (1899). Report on the great earthquake of 12 June 1897, Memoir of Geological Survey of India, 29, 1-379.

Olympa (2014). Earthquake resistant traditional houses of Assam. (https://earthquakeengineeringblog.wordpress.com/2014/05/11/earthquake-resistant-traditional-houses-ofassam/), Accessed: 2021-06-24.

Perry, R.W., M.K. Lindell and K.J. Tierney (2001). Facing the unexpected: Disaster preparedness and response in the United States, Washington, DC, Joseph Henry Press, 1-320.

Platt, S., G. Musacchio, M. Crescimbene, N.A. Pino, D.S. Silva, M.A. Ferreira, C.S. Oliveira, M. Lopes and R. Rupakhety (2018). Development of a Common (European) Tool to Assess Earthquake Risk Communication, In Proceedings of the International Conference on Earthquake Engineering and Structural Dynamics, Reykjavik, Iceland, Springer, 47, 493.

Piangiamore, G.L., G. Musacchio and N.A. Pino (2015). Natural hazards revealed to children: the other side of prevention, Geological Society, London, Special Publications, 419, 1, 171-181.

Poddar, M.C. (1950). The Assam earthquake of 15th August 1950, Indian Miner, 4, 4, 167-176.

Radu, C. (1993). Necessity of training and education in an earthquake-prone country, Report and Summary of Proceedings of the Sixth International Research and Training Seminar on Regional Development Planning for Disaster Prevention, Tsukuba, Japan, 14 December 1992, 57, 15-33.

Ramirez, M. and C. Peek-Asa (2005). Epidemiology of traumatic injuries from earthquakes, Epidemiologic Reviews, 27, 1, 47-55.

Renn, O., A. Klinke and M. Van Asselt (2011). Coping with complexity, uncertainty and ambiguity in risk governance: a synthesis, Ambio, 40, 2, 231-246.

Seeber, L. and J.G. Armbruster (1981). Great detachment earthquakes along the Himalayan arc and long-term forecasting, Earthquake prediction: an international review, 4, 259-277.

Sharma, R., M. Sharma, R. Singh and V. Koushal (2014). SWOT analysis of an Earthquake mock drill: A case study, Int. J. Health Syst. Disaster Manag., 2, 3, 142.

Sinha, R. and A. Goyal (2004). A national policy for seismic vulnerability assessment of buildings and procedure for rapid visual screening of buildings for potential seismic vulnerability, Report to Disaster Management Division, Ministry of Home Affairs, Government of India, Hindistan, 1-9.

Srivastava, H.N. and G.D. Gupta (2004). Disaster mitigation vis-a-vis time of occurrence and magnitude of earthquakes in India, Nat. hHazards, 31, 2, 343-356.

Takeuchi, Y. (2012). East Japan Earthquake and Tsunami: Evacuation, Communication, Education and Volunteerism, Research Publishing Services, 1-288

Tandon, A.N. (1954). Study of the great Assam earthquake of August 1950 and its aftershocks, Indian J. Meteorol. Geophys., 5, 95-137.

Tekeli-Yeşil, S., N. Dedeoğlu, C. Braun-Fahrlaender and M. Tanner (2011). Earthquake awareness and perception of 


\section{Chandan Dey et al.}

risk among the residents of Istanbul, Nat. Hazards, 59, 1, 427-446.

Thingbaijam, K.K.S., S.K. Nath, A. Yadav, A. Raj, M.Y. Walling and W.K. Mohanty (2008). Recent seismicity in Northeast India and its adjoining region, J. Seismol., 12(1), 107-123.

Tillottson, E. (1953). The great Assam earthquake of 1950, In the completion of papers on the Assam Earthquake of August 15, 1950, Compiled by MB Ramachandra Rao, Central Board of Geophysics, Calcutta, India, 94-96.

Tiwari, R.P. (2002). Status of seismicity in the northeast India and earthquake disaster mitigation, ENVIS Bull., 10, $1,15-25$.

Verma, R.K., M. Mukhopadhyay and M.S. Ahluwalia (1976). Seismicity, gravity, and tectonics of northeast India and northern Burma, Bull. Seismol. Soc. Am., 66, 5, 1683-1694.

Verma, M., R.J. Singh and B.K. Bansal (2014). Soft sediments and damage pattern: a few case studies from large Indian earthquakes vis-a-vis seismic risk evaluation, Nat. Hazards, 74, 3, 1829-1851.

Walker, G., R. Whittle, W. Medd and N. Watson (2011). Risk governance and natural hazards, CapHaz-Net Consortium, 1-66.

Yadav, R.B.S., J.N. Tripathi, B.K. Rastogi, M.C. Das and S. Chopra (2010). Probabilistic assessment of earthquake recurrence in northeast India and adjoining regions, Pure Appl. Geophys., 167, 11, 1331-1342.

Yadav, R.B.S., J.N. Tripathi, D. Shanker, B.K. Rastogi, M.C. Das and V. Kumar (2011). Probabilities for the occurrences of medium to large earthquakes in northeast India and adjoining region, Nat. Hazards, 56, 1, 145-167.

Zhao, W., K.D. Nelson, J. Che, J. Quo, D. Lu, C. Wu and X. Liu (1993). Deep seismic reflection evidence for continental underthrusting beneath southern Tibet, Nature, 366, 6455, 557-559.

*CORRESPONDING AUTHOR: Santanu BARUAH,

CSIR-North East Institute of Science \& Technology,

Jorhat, Assam-785006;

and Academy of Scientific

and Innovative Research, Ghaziabad, UP - 201 002,

e-mail: santanub27@gmail.com

(c) 2021 the Author(s). All rights reserved.

Open Access. This article is licensed under a Creative Commons Attribution 3.0 International 